\title{
GUATEMALA Y NUEVA ESPAÑA: HISTORIA DE UNA PLAGA COMPARTIDA, 1798-1807
}

\author{
Luis Alberto Arrioja Díaz Viruell \\ El Colegio de Michoacán
}

Fecha de recepción: enero 2015

Fecha de aceptación: mayo 2015

A finales de julio de 1798, bajo un verano seco y caluroso, las autoridades del reino de Guatemala se dirigieron al Consejo de Indias para notificar las urgencias que enfrentaban debido a la aparición repentina de una plaga de langosta en la porción meridional del territorio. Con el paso de los días, las comunicaciones evidenciaron que dichos insectos se multiplicaban y avanzaban velozmente causando daños irreparables en la cubierta vegetal. Los hechos fueron tan azarosos que, en tan sólo diez meses, los acrídidos se extendieron por todo el reino e incluso alcanzaron la parte sureña de Nueva España. Muy pronto empezaron a llegar a las ciudades noticias de los rincones más remotos de ambos territorios; mientras más información se tenía, más se corroboraban los daños causados en los campos, huertos, bosques y pastizales; daños que, en su conjunto, provocaron escasez de alimentos, incremento de precios, brotes epidémicos y conmociones sociales. ${ }^{2}$

Frente a lo sucedido, las autoridades guatemaltecas y novohispanas no dudaron en desplegar algunos paliativos para aminorar la desgracia; unos, instaron a la población a perseguir y exterminar los insectos; otros, obligaron a los funcionarios a denunciar el acaparamiento y perseguir la especulación de granos; y otros recurrieron

\footnotetext{
1. Esta artículo forma parte de un proyecto de investigación intitulado «México y Guatemala: historia de tres plagas de langosta y el estudio de su impacto ambiental y social (siglos XVIII y XIX)», apoyado por el Consejo Nacional de Ciencia y Tecnología (registro CB-222118).

2. «León, (1798)», Gazeta de Guatemala, n. 74, p. 216; «León, (1798)», Gazeta de Guatemala, n. 89, p. 318; «Informe del alcalde mayor de Cartago sobre una plaga de langosta, (1798)», Archivo Nacional de Costa Rica (en adelante AGCR), Cartago, Exp. 1095; «Circular del gobernador de Costa Rica sobre la plaga de langosta, (1798)», AGCR, Cartago, Exp. 1095.
} 
a las autoridades religiosas para promover rogativas en contra del fenómeno natural. Simultáneamente, intentaron revertir los miedos y desconciertos que los insectos despertaban entre la población. Para ello, discutieron tanto los argumentos naturales como las explicaciones providenciales. Lo anterior dio paso a numerosos escritos, tratados, instrucciones, ordenanzas, bandos, plegarias y conjuros.

Un análisis panorámico de lo acaecido en Guatemala pone al descubierto que la plaga apareció en julio de 1798 y se mantuvo activa hasta septiembre de 1806, especialmente en las tierras bajas que se extendían desde la gobernación de Costa Rica hasta la intendencia de Ciudad Real. Debe tenerse presente que este fenómeno impactó en todos los sectores sociales y económicos del reino. Los añileros de la intendencia de San Salvador, por ejemplo, observaron cómo sus plantaciones sucumbieron ante la voracidad de los acrídidos; los estancieros de las intendencias de Comayagua y León experimentaron la devastación de sus llanos y -por ende- vieron morir una buena cantidad de cabezas de ganado; por su parte, los hacendados de las alcaldías y corregimientos de Guatemala no solo dejaron de cosechar granos sino también padecieron el desamparo de sus tierras al tiempo que los insectos se posicionaron en ellas para reproducirse e inocular sus huevecillos. Obviamente, los estragos fueron más severos entre los pueblos de indios y ladinos que carecían de los medios para producir alimentos y que -en cuestión de meses- perdieron todos los recursos que garantizaban su subsistencia. ${ }^{3}$

En el caso de Nueva España, la plaga de insectos arribó en septiembre de 1801 y se mantuvo con vida hasta diciembre de 1807. Al igual que en Guatemala, los insectos dañaron profundamente los ecosistemas de las intendencias de Oaxaca, Veracruz y Yucatán; asimismo, causaron daños irreversibles en los llanos y manglares de la gobernación de Tabasco. Una muestra inmediata de la catástrofe fue la destrucción de campos, la escasez de alimentos, el acaparamiento de granos y la propagación de enfermedades epidémicas. Dada la porción territorial que afectaron los insectos, no fue casualidad que los pueblos indios de Yucatán, Oaxaca y Tabasco fueran los más perjudicados por este fenómeno.

Como puede observarse, existen paralelos sorprendentes en lo que respecta a la presencia y los efectos que tuvo la plaga en ambos reinos. Sin duda, la aparición y evolución de los acrídidos debe enmarcarse - en términos generales- en lo que la literatura especializada ha denominado la Pequeña Edad del Hielo (PEH) o la Pequeña Edad Glaciar (PEG) y -de manera específica- en una de las oscilaciones que integraron esta secuencia climática -entre 1760 y 1810- y que se caracterizó por presentar irre-

3. «Noticias sobre la existencia del chapulín en los pueblos del reino de Guatemala, (1799-1801)», Archivo General de Centroamérica (en adelante AGCA), A1.22.8.36.4308; «Informes de párrocos sobre la invasión de la langosta en el reino de Guatemala, (1800)», AGCA, A1.11.2450.18878; «Informe del gobernador de Costa Rica sobre la plaga de langosta, (1800)», ANCR, Guatemala, exp. 772; «Sobre la presencia de la langosta en Opico, (1800)», en Correo Mercantil de España y sus Indias, n. 29, p. 225; «Suchitepequez, (1801)», Gaceta de Guatemala, n. 209, ff. 495-497; «Economía civil, (1801)», Gaceta de Guatemala, n. 208, ff. 489-491. 
gularidad térmica en la porción norte del hemisferio, descenso brusco y atípico en las temperaturas, aparición de sequías estivales y olas de calor intenso, y propagación de hidrometeoros y asociaciones de insectos que afectaron la cubierta vegetal. ${ }^{4}$ Los efectos de la plaga, por su parte, deben estudiarse en el horizonte de lo que se denomina «dimensión histórica de los desastres o las castástrofes naturales»; es decir, una perspectiva que no se limita a examinar la plaga en sí misma, sino que presenta y examina el contexto en que surgió y evolucionó con la intención de probar que todo desastre o catástrofe es resultado de la confluencia de factores naturales, sociales, económicos y políticos. ${ }^{5}$

Conviene decir que este tipo de investigaciones se han desarrollado con creces en la historiografía contemporánea, especialmente a la luz de las relaciones que existen entre el hombre y la naturaleza. Muy probablemente, la historiografía norteamericana y española encabezan -hoy en día- los análisis más elaborados sobre esta relación: una, priorizando el análisis del cambio climático y sus repercusiones en las estructuras sociales, económicas y agrarias; otra, interesada en desentrañar esta compleja relación a la luz de la meteorología extrema, la naturaleza atípica, las catástrofes y los desastres naturales, las crisis de subsistencia, la religiosidad popular, etcétera. ${ }^{6}$ Es de advertir

4. Para ampliar el conocimiento sobre este tópico, véase Brian FAGAN, The Little Ice Age. How Climate made History, 1300-1850, London, Basic Books, 2001; John L. Brooke, Climate Change and the Course of the Global History. A Rough Journey, New York and London, Cambridge University Press, 2014; Armando Alberolá Romá, Los cambios climáticos. La Pequeña Edad de Hielo en España, Madrid, Ediciones Cátedra, 2014.. Para el caso específico de México, véase Susana Sosa NAJERA et al., «Registro de sequías históricas en el occidente de México con base en el análisis elemental de sedimentos lacustres: el caso del lago de Santa María del Oro», pp. 437-451, Boletín de la Sociedad Geológica Mexicana, vol. 62, n. 3, 2010; Margarita Caballero y Socorro Lozano García, «La Pequeña Edad de Hielo en el caluroso trópico mexicano», pp. 32-38, Ciencia y desarrollo, n. 31, julio 2008.

5. Para el caso de México y América Central, véase Virginia García Acosta (Coord.), Historia y desastres en América Latina. Vol. I, México, La RED / CIESAS, 1996; Virginia García Acosta, América Molina del Villar y Juan Manuel Pérez Zevallos, Desastres agrícolas en México. Catálogo histórico. Tomo I. Épocas prehispánica y colonial (958-1822), México, Fondo de Cultura Económica / CIESAS, 2003.

6. Para el caso norteamericano, véanse los trabajos siguientes: Brian FAGAN, El gran calentamiento. Cómo influyó el calentamiento climático en el apogeo y caída de las civilizaciones, Barcelona, Gedisa, 2009; Joachim RadKau, Nature and Power. A Global History of the Enviroment, Cambridge, Cambridge University Press and German Historical Institute, 2002; Clive PoInTING, A New Green History of the World. The Enviroment and the Collapse of Great Civilizations, New York, Penguin Books, 2007; J. McNeIll, Something New Under the Sun: An Enviromental History of the Twentieth Century, New York, Penguin Books, 2000; Donald Worster (Edit.), The Ends of the Earth: Perspectives on Modern Enviromental History, Cambridge, Cambridge University Press, 1988. Para el caso español, se recomiendan ampliamente los textos siguientes: Armando Alberola Romá, Catástrofe, economía y acción política en la Valencia del siglo XVIII, Valencia, Institució Alfons el Magnànim, 1999; Armando Alberola Romá, «Procesiones, rogativas, conjuros y exorcismos: el campo valenciano ante la plaga de langosta de 1756», pp. 383-410, Revista de Historia Moderna, n. 21, 2003; Armando Alberola Romá y Jorge OLCINA (Edits.), Desastre natural, vida cotidiana y religiosidad popular en la España moderna y contemporánea, Alicante, Publicaciones de la Universidad de Alicante, 2009; Mariano BARriendos, «La climatología histórica en el contexto universitario español», pp. 41-63, Pedralbes. Revista de Historia Moderna, n. 26, 2006; Mariano BARriendos, «La climatologie historique: aspects méthodologiques. Sa contribution 
que estas reflexiones han sido bien recibidas en la historiografía latinoamericana. En el caso particular de México, buena parte de los trabajos que abordan la relación histórica entre el hombre y la naturaleza se plantean desde perspectivas que priorizan la historia ambiental, la ecología histórica y la historia de los desastres. ${ }^{7}$ Este artículo retoma -de una y otra forma- algunos elementos de los trabajos referidos. De la historiografía española, utilizo los enfoques para reflexionar sobre la PEH en los dominios ibéricos y el interés por estudiar el impacto de las plagas de langosta en las sociedades de antiguo régimen; asimismo, empleo una serie de recursos metodológicos para seleccionar y analizar la documentación primaria que sustenta los argumentos. De la historiografía norteamericana y mexicana, entretanto, aprovecho una serie de ideas para vislumbrar la manera en que los fenómenos naturales adquieren matices y sentidos -políticos, económicos y sociales- que pueden llegar a transformarlos en verdaderos desastres de la naturaleza.

Si bien la presencia de langostas en Guatemala y Nueva España ofrece muchos elementos para contrastar y examinar a partir de los argumentos historiográficos referidos, también es cierto que - a la fecha- solamente un par de trabajos han retomado este fenómeno natural como objeto de estudio y han sugerido algunas propuestas para ahondar en su análisis histórico. ${ }^{8}$ Pese a ello, lo que importa resaltar es que dicha plaga no fue un acontecimiento azaroso e irrelevante. Por el contrario, fue resultado de las pulsaciones climáticas que acarreó la $\mathrm{PEH}$ en su etapa final y tuvo la capacidad de impactar negativamente en las estructuras -económica, política y social- de un amplio territorio. ${ }^{9}$ Inclusive, la gravedad de estos hechos quedaron plasmados en varias

à la reconstruction climatique», pp. 23-39, en F. CLÉMENT (Dir.), Histoire et Nature. Pour une histoire écologique des sociétés méditerranéennes (Antiquité et Moyen Âge), Rennes, Presses Universitaires de Rennes, 2011; Cayetano MAs GalvaÑ, «La gestión de la catástrofe. Acción estatal y lucha contra la plaga de langosta en la diócesis de Murcia y Orihuela (1756-1758)», pp. 51-86, Relaciones. Estudios de Historia y Sociedad, n. 129, 2012.

7. Balances excelentes pueden encontrarse en los siguientes materiales: Bernardo GARCÍA MARTíNEZ y Alba GonzÁlez Jácome (Comps.), Estudios sobre historia y ambiente en América I. Argentina, Bolivia, México y Paraguay, México, El Colegio de México / Instituto Panamericano de Geografía e Historia, 1999; Bernardo García Martínez y María del Rosario Prieto (Comps.), Estudios sobre historia y ambiente en América II. Norteamérica, Sudamérica y el Pacifico, México, El Colegio de México / Instituto Panamericano de Geografía e Historia, 2002; Antonio Escobar Ohmstede (Comp.), La ecología política, la ecología cultural y la historia ambiental a través de Relaciones. Estudios de Historia y Sociedad, México, El Colegio de Michoacán / Fideicomiso Felipe Teixidor y Monserrat Alfau de Teixeidor, 2013; Virginia García Acosta (Coord.), Historia y desastres en América Latina. Vol. I.

8. Para el caso de Guatemala: Martha Few, «Killing Locust in Colonial Guatemala», pp. 62-92, en Martha Few and Zeb ToRTorici (Editors), Centering Animals in Latin American History, Durham and London, Duke University Press, 2013. Para México: Luis Alberto Arrioja Díaz Viruell, «'Enjambres’ y 'nubarrones' en el campo oaxaqueño: las plagas de langosta de 1802 y 1853», pp. 161-213, en Relaciones. Estudios de historia y sociedad, vol. XXXIII, n. 129, Invierno 2012.

9. Cabe decir que durante la segunda mitad del siglo XVIII, estas plagas han sido documentadas en todo el globo terráqueo. Véase: Xavier Sistach, Bandas, enjambres y devastación. Las plagas de langosta a través de la historia, Barcelona, Almazura, 2007; Armando Alberola Romá, «Procesiones, rogativas, conjuros y exorcismos»; D. CAMUfFo y S. EnZI, «Locust invasion and Climatic Factors from the 
publicaciones que circularon por toda la monarquía española, tales como el Correo Mercantil de España y sus Indias, la Gazeta de Madrid, el Semanario de Agricultura y Artes dirigido a los Párrocos, la Gaceta de Guatemala y la Gaceta de México.

A lo largo de este artículo intento contrastar las diversas acciones que se emprendieron en Guatemala y Nueva España para enfrentar la plaga de langosta que invadió sus territorios entre 1798 y 1807 . De la misma manera, examino las posturas que asumieron los funcionarios - civiles y religiosos- para interpretar, contener y administrar la catástrofe natural, y anoto algunos factores -ajenos a la naturaleza de los insectos- que agudizaron los efectos de la plaga. Para ello, utilizo una serie de materiales procedentes de archivos - civiles y eclesiásticos- de México, Guatemala y Costa Rica.

\section{PERSPECTIVAS Y GESTIÓN DE LA CATÁSTROFE}

A principios del siglo XIX, el reino de Guatemala era considerado como la «tierra en el centro de América» y se distinguía por tener una extensa y compleja geografía que servía de morada para 850,000 habitantes, aproximadamente, de los cuales el 70 $\%$ eran considerados indígenas, $18 \%$ eran catalogados como ladinos y $12 \%$ como españoles peninsulares y americanos, negros y mulatos. Como se sabe, el reino se integraba por la capitanía, el gobierno y la audiencia de Guatemala, cuya cabecera se localizaba en la ciudad de Santiago de los Caballeros de Guatemala. A partir de 1786, con las reformas políticas y administrativas de los Borbones, se establecieron cuatro intendencias -Ciudad Real, San Salvador, Comayagua y León- con sus respectivas subdelegaciones y se conservaron dos jurisdicciones: la gobernación de Costa Rica y el corregimiento de Guatemala -con nueve alcaldías mayores y dos corregimientos. Hacia 1803, el reino comprendió 270 pueblos, 10 villas y 3 ciudades (Ciudad Real, Antigua Guatemala y Nueva Guatemala. Asimismo, existían cuatro obispados: Ciudad Real, Comayagua, Guatemala y León, que -a su vez- administraban cerca de 180 parroquias. ${ }^{10}$

Al tiempo en que la plaga se apoderó de la gobernación de Costa Rica y avanzó hacia Nueva España (1798-1801), dicha estructura fue aprovechada para atenuar la

Middle Ages to 1800», pp. 43-73, Theorical and Applied Climatology, n. 43, 1991; Yonglin CHEN y Deer ZHANG, «Historical Evidence for Population Dynamics of Tibetan Migratory Locust and the Forecast of its Outbreak», pp. 135-145, Entolomogia Sinica, vol. 6, n. 2, june 1999.

10. Aaron Pollack, «Introducción», pp. 22-24, en La época de las independencias en Centroamérica y Chiapas. Procesos políticos y sociales, México, Instituto de Investigaciones Dr. José María Luis Mora / Universidad Autónoma Metropolitana, 2013; Carolyn Hall and Héctor PÉRez Brignoli, Historical Atlas of Central America, Norman, University of Oklahoma Press, 2003, pp. 92-93; Bernabé FERnÁNDEZ Hernández, El reino de Guatemala durante el gobierno de Antonio González Saravia, 1801-1811, Guatemala, Comisión Interuniversitaria Guatemalteca de Conmemoración del Quinto Centenario del Descubrimiento de América, 1992, Caps. I y III; Jordana DYM, «Bourbon Reforms and City Government in Central America, 1750-1808», pp. 75-100, en Jordana DYM and Christopher BeLAUBRE (Edits.), Politics, Economy, and Society in Bourbon Central America, 1759-1821, Boulder, University of Colorado Press, 2007. 
emergencia, sacar a la población del fatalismo y planificar acciones contra el insecto. En la fase inicial de la catástrofe, los capitanes generales de Guatemala -José Domas y Valle (1796-1800) y Antonio González Saravia (1801-1811) - se dieron a la tarea de pregonar bandos para enfrentar la emergencia e impedir la falta de provisiones. También ordenaron que las autoridades provinciales se mantuvieran en sus partidos y que los párrocos proporcionaran toda la información posible sobre los insectos. ${ }^{11} \mathrm{Con}$ estas medidas, intentaron contener los intereses de los particulares en el comercio de granos y -de paso- apuntalar el papel de la Corona como beneficiaria de sus súbditos.

La iglesia guatemalteca, por su parte, interpretó y combatió este fenómeno natural a partir de las ideas providencialistas. Sobre esto último, conviene decir que -al tiempo en que apareció la plaga- los párrocos instaron a la población para que se arrepintiera de sus pecados, reconociera el castigo divino e implorara el perdón celestial. Enseguida, realizaron misas, procesiones, novenarios, penitencias y rogativas invocando la intermediación de San Lázaro, San Vicente Ferrer, San Roque y San Francisco de Paula. Así, por más de cinco años, insistieron - una y otra vez- que la plaga era una advertencia para que los feligreses dejaran de pecar; de manera especial, se dirigieron a los indios y las castas por su apego a vivir en la lujuria, el alcohol, la mentira, la ociosidad y la blasfemia; asimismo, dirigieron buena parte de sermones a los hacendados, rancheros y estancieros por su inclinación a explotar el trabajo indígena y alentar la usura en sus tratos comerciales. ${ }^{12}$

Los alcaldes mayores y subdelegados, entretanto, se encargaron de instrumentar al píe de la letra los mandatos girados por los capitanes generales; otros, por su parte, adecuaron dichas órdenes y plantearon medidas -inspiradas en la ilustración- con el objeto de conocer la naturaleza de los insectos, vislumbrar su condición endémica y planificar acciones que rompieran su ciclo biológico. Por ejemplo, don Ventura Calera -alcalde ordinario y corregidor interino de San Salvador- elaboró tres providencias (1800, 1801 y 1803) para contrarrestar los daños causados por la plaga, organizar cuadrillas de trabajadores que exterminaran a los insectos y buscar remedios naturales que trastornaran la reproducción y expansión de los bichos. Simultáneamente, don José Rossi y Rubí -alcalde mayor de Suchitepeques- redactó varios instrumentos para que la población se arrepintiera de sus pecados, asistiera a rogativas y procesiones, bendijera los campos y las sementeras, y practicara cualquier suplica para implorar las clemencias celestiales. En este sentido, Rossi y Rubí sugirió combatir la plaga con las medidas naturales que atenuaban las enfermedades de las plantas; es decir, cubrir los sembradíos con hierbas aromáticas, inundar las tierras afectadas periódicamente y

11. Instrucción del Capitán General dirigida al cabildo eclesiástico y al Real Consulado de Guatemala, (1800)», AGCA, AI.1.17-4306, leg. 36; «Informe del Capitán General del Reino de Guatemala, (1804)», Archivo General de Indias (en adelante AGI), Guatemala, 648, f. 4.

12. Una pequeña muestra de estas conductas puede apreciarse en «Informe de los estragos que ha causado la langosta en Mazatenango, (1802)», AGCA, AI.1.36, 4330; «Langosta o chapulín, (1801)», Gaceta de Guatemala, n. 207, p. 8; «Suchitepeques, (1801)», Gaceta de Guatemala, n. 209; «Sonsonate, (1803)», Gaceta de Guatemala, n. 323. 
-sobretodo- ocuparlas con rumiantes y aves de corral. Por su parte, don José de Valle -abogado de la Real Audiencia de Guatemala- redactó en 1804 la Instrucción sobre la plaga de langosta, medios de exterminarla o de disminuir sus efectos y de precaver la escasez de comestibles. Dispuesta de orden del superior gobierno de Guatemala; es de advertir que dicha instrucción fue una adecuación de dos instrumentos elaborados anticipadamente por la Corona: el Auto acordado por el Consejo Real que comprende las providencias para exterminar la langosta de 1723 y la Instrucción tomada sobre la experiencia y practicada de varios años para conocer y extinguir la langosta en sus tres estados de ovación, feto o mosquito y adulta, con el modo de repartir y prorratear los gastos que se hicieren en este trabajo de $1755 .^{13}$

Conscientes de la gravedad que enfrentaba el reino, los capitanes generales también dispusieron varios medidas para recabar fondos, contener los problemas económicos y paliar las protestas sociales. Dichos instrumentos se elaboraron en la mejor tradición fisiocrática que mostraba a la Corona como garante de la estabilidad económica y precursora de acciones en beneficio de sus vasallos. Uno de ellos instó al cabildo eclesiástico y al Real Consulado de Guatemala para que aportaran cuarenta mil pesos anuales con el objeto de formar cuadrillas en los pueblos «dedicadas a precaver la pública calamidad y general desolación que amaga esta destructora plaga...» Otro obligó a todos los pueblos, villas y ciudades del reino a utilizar los «fondos de comunidad, cofradías, propios y arbitrios... para detener el azote del enemigo...» Otro exigió al Monte Pio de Cosecheros de Añil que destinara veinte mil pesos cada año para invertirlos en el «exterminio de la langosta y en el beneficio público de esta provincia de San Salvador y del reino de Guatemala... ${ }^{14} \mathrm{Si}$ bien es cierto que estas medidas revelaron el compromiso de las instituciones y corporaciones coloniales para erradicar la plaga, también es verdad que evidenciaron la capacidad de las autoridades guatemaltecas para administrar la catástrofe y resarcir los daños causados.

Al tiempo en que los insectos destruían campos y sementeras, el hambre y la desolación se apoderaron de una buena parte del reino. Frente a esto, los capitanes generales se dirigieron a los hacendados y estancieros para pedirles que requisaran todos los granos existentes en sus dominios, remitieran el maíz guardado a las capitales provinciales, velaran por el comportamiento de los precios corrientes y fomentaran los cultivos de tubérculos en las tierras marginales. Desafortunadamente, estas medidas no fueron suficientes para contener la plaga. Ante el avance de los insectos, las auto-

13. «Medidas sugeridas por don Ventura Calera, corregidor de San Salvador, para extinguir la plaga de langosta, (1800-1801)», AGCA, AI.1.17-4306, leg. 36; el «Economía civil, (1801)», Gazeta de Guatemala, n. 208, tomo V, ff. 489-491; Instrucción sobre la plaga de langosta, medios de exterminarla o de disminuir sus efectos y de precaver la escasez de comestibles. Dispuesta de orden del superior gobierno de Guatemala, por el licenciado don José de Valle, abogado de esta Real Audiencia, Guatemala, Impreso por don Ignacio Beteta, 1804.

14. «Instrucción del Capitán General dirigida al cabildo eclesiástico y al Real Consulado de Guatemala, (1800)», AGCA, AI.1.17-4306, leg. 36; «Decreto para que el Montepío de Cosecheros de añil aporte recursos para combatir la plaga (1801)», AGCA, AI.1.17-4306, leg. 36; «Instrucción para que el fondo de Monte Pío destine recursos para destruir la plaga de langosta, (1801)», AGCA, A1. 22-8. 1977. 13473. 
ridades provinciales (intendentes, alcaldes, corregidores y subdelegados) organizaron miles de cuadrillas para emplear a los indios tributarios en la destrucción de los acrídidos y -de paso- proporcionarles recursos para su manutención. De igual forma, las autoridades de la Real Hacienda suspendieron el cobro del tributo en aquellos pueblos que padecían el flagelo y obligaron a los hacendados a responsabilizarse de sus tierras y trabajadores. Aunque es difícil visualizar las reacciones que estas medidas acarrearon entre los sectores involucrados, lo cierto es que las autoridades trataron de probar -a toda costa- que dichas medidas eran las más eficientes y las que garantizaban el orden público.

Como puede observarse, la mayor parte de los funcionarios guatemaltecos respondieron ante la plaga con recursos contundentes. Muy probablemente esto se explica a la luz tres factores. Primeramente, el hecho de que estos hombres conocían perfectamente los alcances y límites que tenían estos insectoos en su reino. Tan sólo tres décadas atrás habían experimentado una plaga que se posesionó en todo el territorio por tres años (1770-1772), causó la muerte de 60,000 personas, provocó que diez pueblos -de la alcaldía mayor de Chiapas y del corregimiento de Guatemala- se deshabitaran y que la producción de cacao enfrentara una crisis brutal. En segundo lugar, las fuentes revelan que estos funcionarios tenían la experiencia suficiente para manejar y administrar este tipo de catástrofes. Cabe recordar que a la plaga de 1770-1772 le siguió el terremoto de 1773 que devastó la ciudad de Santiago de los Caballeros y que obligó a la burocracia a emprender un programa para administrar la desgracia y -de paso- reconstruir la capital del reino en un paraje más seguro. En tercer lugar, el hecho de que la plaga de 1798-1807 impactó sobre uno de los ejes vertebrales de la economía centroamericana: la producción de añil. Desde mi perspectiva, este factor fue determinante para que los funcionarios guatemaltecos atendieran la catástrofe y -sobretodo- invirtieran conocimientos y recursos para frenar el avance del insecto; un avance que no solo mermó las economías de subsistencia, sino también la economía mercantil que soportaba -vía impuestos y actividades comerciales- las finanzas públicas del reino. Cabe mencionar que para estos años, el comercio de añil o xiquilite de San Salvador, Guatemala y Comayagua representaba el $85 \%$ de las exportaciones centroamericanas que llegaban a Cádiz; asimismo, se consideraba que -despues de la plata y la cochinilla novohispanaera uno de los bienes más demandados en los mercados europeos. ${ }^{15}$

Frente a estos hechos, conviene revisar y contrastar la experiencia de Nueva España. Hacia el periodo 1794-1800, el sureste de este virreinato era considerado uno

15. Para tener una idea general de estos problemas, véanse las siguientes obras: Juan Carlos Solorzano FONSECA, «Los años finales de la dominación española, 1750-1821», pp. 13-140, en Historia General de Centroamérica, tomo III. De la Ilustración al liberalismo, San José, Facultad Latinoamericana de Ciencias Sociales, 1994; Christopher H. Lutz, Santiago de Guatemala, 1541-1773: City, Caste and the Colonial Experience, Norma, University of Oklahoma Press, 1994; José Antonio Fernández MolinA, Pintando el mundo de azul. El auge añilero y el mercado centroamericano, 1750-1810, San Salvador, Dirección de Publicaciones e Impresos / Consejo Nacional para la Cultura y el Arte, 2003; Sajid Alfredo Herrera Mena, El ejercicio de gobernar. Del cabildo borbónico al ayuntamiento liberal. El Salvador colonial, 1750-1821, Castelló, Universidad Jaume I, 2013. 
de los escenarios más poblados y con el mayor número de asentamientos indígenas. Tan solo una suma simple de las cifras demográficas en las intendencias de Oaxaca y Yucatán dan como resultado 1,000,000 de habitantes, aproximadamente, de los cuales más del $80 \%$ eran considerados indígenas y el resto catalogados como castas y españoles. Centrando la atención en la intendencia de Oaxaca, puede decirse que existían 22 subdelegaciones, 933 pueblos de indios, 5 villas y una ciudad. En el caso de la intendencia de Yucatán, desde 1786, se establecieron 13 subdelegaciones que -a su vez- administraron 224 pueblos de indios, 2 villas y una ciudad. Algunas referencias indican que -hacia 1794- la gobernación de Tabasco disponía de 2 villas, 53 pueblos, 9 parroquías, 200 haciendas y 523 ranchos. ${ }^{16}$ En lo que respecta a la geografía eclesiástica, todo este territorio comprendió dos obispados: Antequera de Oaxaca y Mérida de Yucatán. ${ }^{17}$

Al igual que en el reino de Guatemala, dicha estructura fue crucial para trazar acciones en contra de la langosta. No obstante, a diferencia de lo sucedido en América Central, las autoridades novohispanas desplegaron medidas acordes a su realidad. La primera de ellas fue enarbolada por los virreyes Féliz Berenguer de Marquina (18001803) y José de Iturrigaray y Arostegui (1803-1808), y se caracterizó por mostrar contenidos opacos ante la catástrofe, al grado de plantearla como una amenaza menor para la agricultura y la economía novohispana; inclusive, en repetidas ocasiones, estas acciones se encargaron de atenuar los efectos de la plaga, responsabilizar a los pueblos de la desgracia y delegar en los funcionarios distritales la resolución del problema. Tal fue su indiferencia que, incluso, las instrucciones giradas al respecto fueron una copia fiel de las utilizadas por el Consejo de Castilla en 1754-1755 para combatir una plaga de langosta en la península y de las empleadas por la Cámara del Virreinato en 17851786 para enfrentar la sequía en Nueva España. ${ }^{18}$ Por si esto no fuera suficiente, muy pronto prohibieron la circulación de dichos instrumentos por considerar que la plaga se había extinguido. No obstante, las fuentes revelan que el problema continuó y se agudizó, al grado de que buena parte de los territorios de Tabasco, Oaxaca y Yucatán enfrentaron el desabasto de granos.

La segunda medida fue protagonizada por intendentes y subdelegados, y se distinguió por desplegar acciones sistemáticas y planificadas contra los insectos; acciones

16. Jorge Gurría LaCroix, «La población de la provincia de Tabasco durante el virreinato», pp. 1-25, Estudios de Historia Novohispana, vol. VI, n. 6, 1978.

17. Enrique Florescano y Margarita Menegus, «La época de las reformas borbónicas y el crecimiento económico (1750-1808)», pp. 363-430, en Historia general de México. Versión 2000, México, El Colegio de México, 2000; Dorothy TANCK De Estrada, Pueblos de indios y educación en el México colonial, 1750-1821, México, El Colegio de México, 1999; Beatriz Rojas, «Orden de gobierno y organización del territorio: Nueva España hacia una nueva territorialidad, 1786-1825», pp. 131-163, en Clara GARCíA Ayluardo (Coord.), Las reformas borbónicas, 1750-1808, México, Fondo de Cultura Económica / CIDE / CONACULTA / INEHRM, 2010.

18. «Bando para conocer y extinguir la langosta en sus tres estados, (1802)», Archivo General de la Nación (en adelante AGN), Bandos, vol. 22, exp. 63; Noticia de las providencias dictadas para el exterminio de la plaga de langosta, (1803)», AGN, Bandos, vol. 23, exp. 40. 
que, desde una óptica racionalista, alertaron sobre los daños económicos y las medidas que debían tomarse para reducir la desgracia. Sin duda, las acciones instrumentadadas por dichas autoridades fueron mucho más comprometidas y eficientes respecto a las mostradas por los virreyes. En efecto, los intendentes y subdelegados de Oaxaca y Yucatán fueron los articifices de un programa que -entre 1801 y 1807- persiguió a los insectos en su etapa endémica, organizó cercos preventivos y cuadrillas de exterminio, y remedió el acopio de alimentos en villas y pueblos. Como parte del programa se desprendieron las Reglas dictadas por el intendente de Oaxaca para el exterminio de la langosta (1804); la destrucción de 15,000 arrobas de insectos a manos del intendente de Yucatán -don Benito Pérez y Valdelomar- y del subdelegado de Sahcabcthen -don Pedro de Elizalde; y el abasto de granos en los partidos de Villahermosa, Jalapa, Tacotalpa y Teapa a manos del síndico procurador de Tabasco -Antonio de Alías y Franco. ${ }^{19}$

La tercera medida fue protagonizada por la iglesia novohispana,. A diferencia de lo acaecido en Centroamérica, una parte del clero novohispano instó a sus párrocos para que imploraran la ayuda celestial, se combatiera la plaga con rezos y acciones en el campo, y se recolectaran recursos para ayudar a los pueblos más afligidos. En este orden, el obispo de Antequera -Antonio Bergoza y Jordán (1801-1813) publicó varios edictos con la intención de que sus dicocesanos persiguieran, recolectaran y extinguieran la mayor cantidad de insectos y canutillos a cambio de pagar diez pesos por cada arroba que entregaran en las parroquias. ${ }^{20}$ Algo semejante impulso el obispo de Yucatán -Pedro Agustín Estévez y Ugarte (1797-1827) - al tiempo en que acordó con las autoridades políticas que los indios afectados se dieran a la tarea de extinguir estos insectos a cambio de que los párrocos y subdelegados liquidaran 5 pesos por cada costal de insectos entregado; asimismo, que destinaran un porcentaje de los recursos acumulados en las cofradías indígenas para organizar y costear cuadrillas que erradicaran los huevecillos y larvas del chapulín. ${ }^{21}$

Según puede leerse, las conductas de las autoridades y los religiosos de Nueva España fueron contrastantes: mientras los virreyes desentendieron -en cierta medidael problema, los funcionarios intermedios y los religiosos trataron de remediar la desgracia. Obviamente, esto tuvo varias explicaciones. Durante las fechas en que la plaga infestó el sureste del virreinato, Berenguer e Iturrigaray se ocuparon en disipar los problemas acarreados por las guerras atlánticas (1796-1802 y 1805-1807) y, específi-

19. «Reglas dictadas por el intendente de Oaxaca para el exterminio de la langosta, (1804)», AGN, Civil, vol. 1701, exp. 3; «Informe de las actividades realizadas por el intendente de Yucatán para combatir la plaga de langosta (1804-1805)», AGN, Civil, vol. 1707, exp. 1; «Cuenta general de lo gastado en el partido de Chicbul para el exterminio de la langosta, (1804-1805)», AGN, Civil, vol. 1349, exp. 1; «Informe del Síndico Procurador de Tabasco sobre los daños causados por la plaga de chapulines, (1804-1805)», AGN, Civil, vol. 2273, exp. 1.

20. «Langosta en Oaxaca, (1802)», Gazeta de Guatemala, no. 274.

21. «Expediente formado sobre la matanza de langosta y premio señalado a los matadores, en Yucatán, (1804)», AGN, Civil, vol. 1707, exp. 4. 
camente, en atender las solicitudes crediticias de la metrópoli y la provisión de situados para los territorios de América Central y el Gran Caribe. ${ }^{22}$ En contraste, los intendentes y subdelegados, así como los religiosos, fueron los responsables de regular la vida diaria en las provincias y localidades, y -por ende- de resolver todas las contrariedades que acarreaban los fenómenos naturales, las enfermedades epidémicas, los conflictos sociales, etcétera. De ahí, entonces, que su postura frente a la plaga fuera más decidida y eficiente. Además, como en el reino de Guatemala, estos burócratas padecieron la plaga de 1770-1772 y -de alguna forma- acumularon conocimientos para sortear la adversidad y administrar la desgracia.

Un balance de las perspectivas y las acciones desplegadas respecto a la plaga en ambos reinos, pone al descubierto que las autoridades civiles y religiosas trataron de enfrentar esta catástrofe con ideas gestadas en la mejor tradición fisiocrática y providencialista, con instrumentos inspirados en los Autos y las Instrucciones que tiempo atrás se habían ejecutado en la península y con medidas que pretendían restaurar el orden público, garantizar la subsistencia de los individuos y admistrar -en lo posible- las secuelas de la desgracia. Pese a que dichas disposiciones cobraron efecto en ciertos espacios y momentos, las fuentes revelan que la plaga ganó en dinamismo y se mantuvo vigente en ambos reinos hasta 1806 y 1807, respectivamente. Frente a este escenario, cabe preguntarse ¿Qué factores alentaron el desarrollo de la catástrofe y cómo respondieron las autoridades y los habitantes al respecto?

\section{LA COMPLEJIDAD Y LOS ALCANCES DEL DESASTRE}

Como suele ocurrir en todos los desastres naturales, los paralelismos que en un primer momento existieron entre la experiencia guatemálteca y novohispana desaparecieron rápidamente con el paso del tiempo. Si bien la plaga de langosta gestó un escenario donde convivieron el hambre y la enfermedad por doquier, también es verdad que -entre 1798 y 1807- dicha miseria se agudizó desigualmente. Aunque algunas fuentes advierten que la plaga creció al tiempo en que los insectos se multiplicaron indiscriminadamente, lo cierto es que dicha proliferación fue resultado de factores ajenos a la naturaleza de los insectos. Una lectura panorámica de las fuentes resguardadas en los archivos centroamericanos pone de relieve que un hecho importante en la propagación tuvo que ver con las conductas asumidas por los hacendados y rancheros de las intendencias de San Salvador y Comayagua, y de los corregimientos y alcaldías de Guatemala. Como ha demostrado la historiografía especializada, los años de malas cosechas fueron -paradójicamente- las temporadas más benéficas para

22. Véanse Instrucciones y memorias de los virreyes novohispanos, tomo II, México, Editorial Porrúa, 1991, pp. 1373-1505; Carlos MARICHAL, «La economía de la época borbónica al México independiente, 17601850», pp. 192-194, en Sandra KunTz (Coord.), Historia económica general de México. De la Colonia a nuestros días, México, El Colegio de México / Secretaria de Economía, 2010; Carlos MarichaL y Matilde Souto, «Silver and Situados: New Spain and the Financing of the Spanish Empire in the Caribbean in the Eighteenth Century», pp. 587-613, en Hispanic American Historical Review, n. 74, 1994. 
los hacendados, toda vez que eran momentos idóneos para vender productos a precios elevados, acaparar las semillas existentes y establecer condiciones en los mercados agrarios; obviamente, esta situación provocaba que la población enfrentara la carestía y desabasto de mercancías. No obstante, la documentación revisada revela que el reproche hacia los hacendados no sólo fue por sus conductas especuladores, sino también por impedir que sus trabajadores colaboraran en las tareas de persecución y extinción del insecto. Sin duda, la negativa de los hacendados y rancheros tuvo fundamentos muy claros. ${ }^{23} \mathrm{El}$ primero de ellos implicó un rechazo profundo a las órdenes reales que obligaban a los trabajadores de haciendas -entre 12 y 60 años-a recorrer diariamente los campos en busca de insectos para luego exterminarlos en presencia de las autoridades políticas. El segundo tuvo que ver con la resistencia a «contribuir y mantener las cuadrillas de gente que se destinan proporcionalmente a las fincas cada semana para destruir el chapulín...» ${ }^{24} \mathrm{El}$ tercero tuvo como trasfondo una reflexión meramente económica; es decir, los hacendados dejaron crecer la catástrofe con el objeto de que los precios de sus productos se incrementaran en el mercado y -de esta manera- recuperaran parte de las pérdidas que habían experimentado desde 1790 por las recurrentes sequías y heladas en el reino (1790, 1792-1793 y 1797-1798), por los trastornos comerciales en el Caribe centroamericano (1796-1800) y por la contracción de los mercados del añil desde 1786-1787. Sea de ello lo que fuera, lo cierto es que las posturas asumidas por los hacendados coadyuvaron para que los insectos reprodujeran su ciclo biológico y -por ende- avanzaran sobre la geografía del reino, al grado de posicionaser sobre una franja territorial que iba en línea recta desde la península de Nicoya - en la gobernación de Costa Rica- hasta las tierras bajas del Soconusco -en la intendencia de Ciudad Real. Es de advertir que esta conducta desplegada por los hacendados fue tolerada -en algunos momentos- por las autoridades del reino, toda vez que dicho sector representaba una fuerza para la economía y un punto de estabilidad para la política guatemalteca. Sin embargo, las secuelas de esta tolerancia no solo implicaron la expansión geográfica de los acrídidos sino también la ruina completa de la producción de añil en San Salvador y Guatemala; ruina que persistió hasta la tercera década del siglo XIX. ${ }^{25}$

23. Algunas fuentes que muestran estas conductas y críticas son: «Providencia para que el alcalde mayor de Totonicapan y Huehuetenango rinda periódicamente informes sobre la existencia o no de la plaga de langosta, (1805)», AGCA, A1. 22. 6091. 55307; «Instancia del común de Jacaltenango para destinar parte de sus fondos de comunidad para adquirir víveres, (1805)», AGCA, A1.73. 2805. 24649; «Exoneración del pago de alcabala y diezmos a todos los cosecheros de xiquilite, cacao, algodón, café y caña de azúcar en las provincias de Comayagua, Nicara gua y San Salvador, (1805)», AGCA, A1. 23. 2317. 96; «Informe sobre las cosechas de añil, (1806)», Correo Mercantil de España y sus Indias, n. 77, p. 25; «Composición de la familia Esponda por capitales piadosos, (1806)», Archivo Histórico Diocesano de San Cristóbal (en adelante AHDSC), Tuxtla, carpeta 3339, exp. 3

24. «Informe sobre la situación que se experimenta en el reino de Guatemala a causa de la langosta, (1803)», ANCR, Cartago, Exp. 957.

25. Una buena perspectiva de esta situación puede encontrarse en AGCA, AI.1.17-4306. 36. 
En lo que respecta a Nueva España, las fuentes revelan que el problema de la langosta ganó dinamismo al tiempo en que la plaga creció en los territorios centroamericanos y-consecuentemente- migró al sureste novohispano. Sin duda, este hecho fue determinante para que la desgracia se agudizara, aunque no fue un factor exclusivo. Revisando los materiales procedentes de Oaxaca, Tabasco y Yucatán, salta a la vista que algunos pueblos y autoridades se mostraron indiferentes y confusos respecto a los insectos. Entre 1803 y 1804, por ejemplo, los subdelegados de Zimatlán y Tehuantepec desatendieron los extrañamientos del intendente de Oaxaca y dejaron que la plaga avanzara libremente por sus jurisdicciones. Hasta donde puede observarse, dichos subdelegados prefirieron concentrar su atención en los repartimientos de mercancías y dejaron en segundo plano las acciones contra los insectos. Lo anterior provocó que el intendente arremetiera en su contra y tomara cartas en el asunto. Ante esto, los subdelegados respondieron disculpándose por «no haber tenido noticia de la entrada de la langosta en los pueblos del distrito, pero que en vista de las instrucciones recibidas había expedido las convenientes para que estos pueblos se hallen prevenidos de la langosta...» Desde la postura del intendente, estas respuestas fueron innecesarias toda vez que el insecto invadió las jurisdicciones y provocó daños graves en la agricultura, al grado de escasear los granos entre la población. ${ }^{26}$

Otro caso de desgano ocurrió en la gobernación de Tabasco entre 1804 y 1805. En aquella ocasión, los naturales de Teapa se dirigieron al síndico procurador para hacer de su conocimiento que los vecinos del pueblo se negaban a combatir la plaga aduciendo que carecían de recursos para sumarse a las cuadrillas de trabajo. También expresaron que, en caso de persistir la negativa entre los vecinos, se corría el riesgo de que otros pueblos «imitaran su ejemplo y se daría el caso de que no hubiese gente con quién perseguir dicho insecto...» Ante este problema, el síndico procurador sancionó económicamente a los vecinos responsables y amenazó con cárcel a la población -en general- en caso de negarse a perseguir a los insectos. ${ }^{27}$

Otro hecho peculiar se suscitó en la intendencia de Yucatán, donde los subdelegados de la Costa y la Sierra Alta enfrentaron una serie de acusaciones por desobedecer los mandatos reales y negarse a combatir la plaga de langosta. Hasta donde puede observarse, dichas autoridades estaban estrechamente relacionadas con el abasto de maíz a los pueblos, villas y ciudades de Yucatán. De ahí que la presencia de la plaga se tornara en una oportunidad para controlar el mercado de semillas, incrementar sus precios y lucrar con la demanda de los más necesitados. ${ }^{28}$

26. «Extractos de noticias recibidas sobre la langosta y las prevenciones hechas con este motivo, (1803)», AGN, Civil, vol. 1701, exp. 1, ff. 105-106, 110-111.

27. «Testimonio de representación del Síndico Procurador de Tabasco, (1805)», AGN, Civil, vol. 2273, exp. 1.

28. «Noticias y acuerdos sobre el abasto de granos, (1800-1805)», en Biblioteca del Museo Nacional de Antropología e Historia (en adelante BMNAH), Serie Yucatán, Rollo de micropelícula 6, Archivo del Cabildo de la Ciudad de Mérida, Libros de Acuerdos. 
Este tipo de noticias continuaron vigentes en buena parte del sureste novohispano hasta septiembre-octubre de 1806; posteriormente, ganaron terreno aquellas que referían las lluvías torrenciales y el descenso de temperaturas. Tengo la impresión de que esta alteración climática impactó en el ciclo de vida de los artrópodos, pues -desde la perspectiva de los entomólogos- cuando la cubierta vegetal era abundante, las temperaturas altas y las lluvias esporádicas, la langosta encontraban las mejores condiciones para nacer, crecer y multiplicarse; no obstante, cuando las temperaturas bajaban y las lluvias aumentaban los insectos morían sin alcanzar su condición gregaria. $^{29}$

Así las cosas, puede decirse que los hechos climáticos que se presentaron en Guatemala y Nueva España -entre 1806 y 1807- contuvieron el avance de la plaga y acarrearon cierto sosiego para los pueblos. Lo anterior fue documentado indirectamente por el subdelegado de Teutila en la intendencia de Oaxaca al referir -en 1806-que: «librados de la langosta... ahora hemos perdido las milpas casi seguidamente, ocasionando este daño el frío..., y por eso me he visto en la estrecha y penosa necesidad de recurrir a su socorro desde fines del año de 1805 hasta el presente...» Un argumento muy parecido proporcionó el párroco de San Mateo Tila -Mariano Solís- en la provincia de Chiapa al referir que, luego de haber padecido por más de cinco dicha plaga, comenzaba a experimentarse una profunda decadencia en las mangas de langosta ya que las lluvías y los fríos invernales «no perdonan la vida del chapulín... y provocan que muera escarchado o ahogado... $\rangle^{30}$

Sea de ello lo que fuera, lo cierto es que -entre 1806 y $1807-$ los reinos de Guatemala y Nueva España experimentaron un periodo de remisión, durante el cual no irrumpieron plagas de langosta a gran escala. Muy probablemente, esto tuvo que ver con la variabilidad térmica e hidrológica observada en el penúltimo ciclo de la denominada PEH; un ciclo que se manifestó en el espacio de estudio con sequías, calores y plagas durante el periodo 1794-1810; con bajas de temperaturas y aumento sustancial de precipitaciones entre 1812 y 1830 ; y con episodios de calor extremo, sequías, epizotías y plagas entre 1851 y 1857.

\section{CONCLUSIONES}

Los paralelismos que desató el ataque de una plaga de langosta en el reino de Guatemala y en el sureste de Nueva España -entre 1798 y 1807-son propios de estudiarse en un horizonte historiográfico que contemple, por un lado, la fluctuación climática que implicó la PEH y, por otro lado, la dimensión histórica de los desastres y las catástrofes naturales. Como se ha observado, los insectos destruyeron buena parte

29. Antonio Buj Buj, «La plaga de la langosta. Permanencia de un riesgo biológico milenario», pp. 4-8, en Scripta Nova. Revista electrónica de geografia y ciencias sociales, vol. XII, n. 270, agosto de 2008.

30. «Sobre el embargo de recuas para conducir maíz a la jurisdicción de Teutila, (1805-1806)», AGN, Civil, vol. 1416, exp. 5; «Informe del párroco de San Mateo Tila sobre la plaga de langosta, (1807)», AGCA, AI.73. A3.40, 4365. 335 . 
de los campos de labranza en ambos territorios, generaron hambre, miedo y desolación entre la población, pusieron en alerta a las autoridades y propiciaron una serie de trastornos en las economías regionales. En este orden, la plaga también propició que se plantearan numerosos escritos y reflexiones que intentaron explicar sus alcances y limitaciones, ya sea a la luz de argumentos naturalistas, providencialistas o económicos.

Una diferencia clara entre la experiencia guatemalteca y novohispana radica en que la plaga invadió y causó estragos en todo el reino de Guatemala y -por ende- propició que las autoridades de todos los niveles de gobierno se involucraran plenamente en las tareas de reconocimiento, contención y exterminio; tareas que realizaron de forma comprometida y eficiente, toda vez que advertieron la capacidad endémica de la plaga y los daños que acarreaba para la economía del reino. Sin duda, este compromiso no se percibió en los virreyes novohispanos. Las fuentes muestran que Berenguer e Iturrigaray delegaron la gestión de la catastrofe en los intendentes y subdelegados de las zonas afectadas, mientras ellos centraron su atención en la resolución de los problemas acarreados por las guerras atlánticas y en la provisión de situados y recursos para las colonias caribeñas y centroamericanas. Sin duda, la metrópoli respaldó estas posturas y confiaron en que las autoridades guatemáltecas y novohispanas solucionaran los problemas económicos y sociales que provocó el fenómeno natural.

Otro punto de contraste estriba en los factores que posibilitaron el desarrollo de la plaga. Mientras en el reino de Guatemala la negativa de los hacendados y rancheros a facilitar la fuerza de trabajo y los recursos económicos para exterminar los bichos fue determinante, en Nueva España las razones se anclaron en las conductas apáticas de autoridades y pueblos para combatir los acrídidos. Otro aspecto comparable se encuentra en las posturas y acciones que desplegó la Iglesia frente al avance de los insectos. En este sentido, tanto los obispos de Guatemala como de Nueva España se mostraron proclives a exterminar esta plaga biblica con rezos, rogativas, procesiones, exhorcismo y trabajos físicos. Finalmente, puede decirse que la naturaleza gregaria de los insectos no fue el único factor destructivo para el campo novohispano y guatemalteco entre 1798 y 1807; resulta evidente que las posturas desplegadas por ciertos actores económicos -como los hacendas salvadoreños y guatemáltecos- y políticos -como los subdelegados y algunos pueblos de indios-jugaron un papel importante en la gestación y el desarrollo de este desastre. 